\title{
Interacting environmental stressors modulate reproductive output and larval performance in a tropical intertidal barnacle
}

\author{
Florian Freuchet ${ }^{1}$, Réjean Tremblay ${ }^{1}$, Augusto A. V. Flores ${ }^{2, *}$ \\ ${ }^{1}$ Institut des sciences de la mer-Université du Québec à Rimouski, 310 allée des Ursulines, Rimouski, Québec G5L3A1, Canada \\ ${ }^{2}$ Universidade de São Paulo, Centro de Biologia Marinha (CEBIMar/USP), Rod. Manoel Hipólito do Rego, km 131.5, \\ 11600-000, São Sebastião, São Paulo, Brazil
}

\begin{abstract}
Tropical intertidal filter-feeding invertebrates often face thermal stress and oligotrophic nearshore conditions, which may modulate reproductive responses. In order to investigate how these stressors affect resource allocation for reproduction, we first acclimated experimental populations of the higher shore barnacle Chthamalus bisinuatus to different levels of food supplies, to obtain baseline reproductive parameters, and then submitted them to consecutive stress events, by transferring populations to chambers where temperature was either unchanged $\left(25^{\circ} \mathrm{C}\right)$ or increased to critical levels $\left(45^{\circ} \mathrm{C}\right)$. Thermal stress decreased overall adult survival by $15 \%$ and overall larval release by $53 \%$, while no significant effects of food shortage were detected. Experimental populations after moderate short-term stress events (transfer to control chambers) showed anticipatory fitness effects by increasing both the quantity and the quality of larvae, which survived longer without an exogenous food supply. After severe stress, parents first decreased larval release rate (thermal stress) and then produced lower-quality larvae (thermal stress plus food shortage), compatible with a selfish strategy. Lipid analyses showed that adults are very efficient in retaining essential fatty acids (EFAs) and capable of fast accumulation of reserve lipids shortly after stress, which however decreased over the experiment. Chronic stress led to decreased transfer of reserve lipids to larvae, and increased transfer of EFAs, suggesting a compensatory effect on larval quality. Populations exposed to both stressors lacked these temporal trends and produced low-quality nauplii. Unexpectedly, parental manipulation seems to involve the allocation of EFAs, not reserve lipids, as usually reported for lecithotrophic larvae.
\end{abstract}

KEY WORDS: Parental effects - Reproductive investment $\cdot$ Planktotrophic larvae $\cdot$ Life-history tactics $\cdot$ Reproductive strategy $\cdot$ Offspring manipulation $\cdot$ Rocky shore

- Resale or republication not permitted without written consent of the publisher

\section{INTRODUCTION}

Several processes, reviewed by Morgan (1995), are responsible for exceedingly high mortality rates in the plankton (Rumrill 1990), and starvation stands out as one of the most important causes, especially for crustacean larvae (Olson \& Olson 1989). Therefore, parental resource allocation to offspring, although insufficient to ensure development to competent lar- val stages, may be important to prevent starvation during temporary poor trophic conditions (McEdward 1986, Poorbagher et al. 2010). Because life-history tables for benthic stages and information on larval mortality rates are usually not available, it is difficult to predict optimal resource allocation to offspring as a strategy to maximize fitness over their lifespan (McEdward 1986, van Noordwijk \& de Jong 1986, Kozlowski 1992, Bertram \& Strathmann 1998, Poor- 
bagher et al. 2010). However, knowing how adult populations regulate reproductive output when facing critical environmental conditions may help us to understand the ways in which selection has shaped adaptive life-history traits in intertidal habitats.

During reproduction, females of many invertebrate species inhabiting relatively unstable habitats are capable of rapidly transferring energetic resources to developing oocytes, as a response to stochastic environmental triggers (Eckelbarger 1994). Over their breeding lifetime, females can manipulate the energetic resources they allocate to their brood, usually by the transfer of lipids (Yamamoto et al. 1999). However, maternal resources can be allocated in different ways during egg production, as reviewed by Marshall \& Uller (2007). Besides compensatory responses to physiological constraints, mothers can also use environmental cues to manipulate resource allocation to individual offspring, thus adding another component of phenotypic variation in their offspring, and providing a mechanism for adaptive transgenerational phenotypic plasticity (Mousseau \& Fox 1998). Under reliable signaling of habitat quality, mothers may either enhance ('anticipatory maternal effects', AME) or reduce ('selfish maternal effects', SME) offspring fitness. Under unpredictable environmental conditions, selection may favor mothers which produce offspring with a range of phenotypes to maximize the probability of their broods surviving ('bet-hedging maternal effect', BME). AME, SME and BME increase maternal fitness but only AME enhance offspring fitness (Marshall \& Uller 2007). Mothers may also buffer environmental variation by either reducing their own growth and/or metabolic activity or by reducing fecundity (physiological side-effects) (Mousseau \& Dingle 1991, Groothuis et al. 2005). Under extremely unfavorable conditions, posing exceptionally high mortality risk for adults, energy resources can be rapidly directed to reproduction, making possible a terminal investment (Cotter et al. 2011). Risk cues, such as activation of the immune system (signaling infections; Cotter et al. 2011), injuries (Javoiš \& Tammaru 2004) or extreme weather events (Roitberg et al. 1993) can trigger a terminal reproductive investment, thus increasing fitness under conditions of low life expectancy. As far as we are aware, there is no information on how mothers manipulate planktotrophic offspring quality when facing life-threatening stressors, and how such a response depends on available resources.

Sessile animals inhabiting intertidal coastlines in tropical regions may face several environmental stressors. In spite of remarkable adaptations to cope with heat stress, sessile benthic species may be unable to control their body temperature over certain thermal thresholds. Extreme temperatures of ca. $50^{\circ} \mathrm{C}$, as occurring at the surface of rocky shores (Williams 1994), may lead to even higher body temperatures of several different organisms (Lewis 1963, Achituv et al. 1980, Williams \& Morritt 1995, Chan et al. 2006). In the case of the volcano barnacle Tetraclita japonica, the internal temperature can be $15 \%$ higher than surface rock temperature, which is well beyond the tolerance of this species and may be the cause of mass mortality (Chan et al. 2006). Thermal stress may also explain large mortality events observed in other barnacle populations (Thiyagarajan et al. 2000). Also, oligotrophic conditions in coastal tropical oceans are common (Marañón et al. 2000, Palmer \& Totterdell 2001) and food supply for filter-feeding benthic stages may be limited (Kasten \& Flores 2013). The acorn barnacle Chthamalus bisinuatus (Pilsbry) is the dominant organism in the upper midlittoral zone along rocky coastlines in south-eastern Brazil, with cover densities ranging from $\sim 50$ to $>80 \%$ (Christofoletti et al. 2011). Previous research on this species showed that both food supply and temperature were positively correlated with naupliar release in natural conditions (Kasten \& Flores 2013). Based on the time required for a reproductive response, these authors hypothesized that food supply could be limiting reproductive output in the São Sebastião Channel (SSC), and that release events could also be triggered by sub-lethal temperatures, consistent with a terminal reproductive investment. However, testing of causal mechanisms is still pending.

Several studies have addressed the effects of temperature and food availability on different aspects of barnacle reproduction (e.g. Desai \& Anil 2005, Leslie et al. 2005, Berger 2009, Inatsuchi et al. 2010, Yuen \& Hoch 2010), but a trade-off analysis allowing identification of reproductive strategies under extreme but realistic stressful settings is still lacking. In the laboratory experiments of the present study, the main objective was to understand how adults of the barnacle $C$. bisinuatus partition resources when producing their larvae under contrasting environmental conditions. In a factorial experiment, we manipulated food supply and thermal stress in adult populations in order to understand reproductive strategies under critical conditions that may frequently impact barnacle populations in the field. As response variables, we measured the performance of adults and their larvae, and also lipid profiles of both ontogenetic stages. While adult growth, survival and larval release rate may provide ultimate outcomes of resource alloca- 
tion for adult maintenance and offspring production, lipid analyses may identify physiological restrictions or mechanisms by which adults manipulate offspring quality. The accumulation of fatty acids (FA) and their profiles have been used as physiological indicators of adult and larval quality because lipids are the primary source of energetic reserves (Lucas et al. 1979, Thiyagarajan et al. 2003). In an anticipatory strategy, adult barnacles would transfer relatively larger amounts of neutral lipids to their larvae, mostly triacylglycerides (TAG), since their supply is correlated to both larval survival and metamorphosis success (Thiyagarajan et al. 2002, Pernet \& Tremblay 2004, Tremblay et al. 2007b). Essential fatty acids (EFAs), in contrast, may not be used as an energy source but their transfer to larvae may be critical for several physiological processes - such as cell synthesis, neural development, endocrine function and control, ionic regulation, immune function and reproduction (see Glencross 2009 for a review).

An overall analysis of our results allowed us to interpret responses of the parental population in the light of 3 alternative hypotheses: (1) adult barnacles (parents) cannot manipulate larval quality, and changes to both brood size and adult physiological state are a result of physiological constraints (PC); (2) parents can manipulate larval quality in addition to $\mathrm{PC}$, and anticipate adult fitness by allocating additional per-capita resources to offspring when environmental conditions are unfavorable; (3) parents manipulate larval quality under critically stressful conditions, and independently of any PC, they decrease per capita resource allocation to offspring and ensure their own performance. Identifying the strategy followed by this ecologically important barnacle species will allow us to test more specific questions on patterns of offspring production and predict breeding potential according to environmental change.

\section{MATERIALS AND METHODS}

\section{Sampling of adult populations}

We sampled the upper midlittoral, i.e. the higher barnacle zone, of rocky shores to obtain our experimental populations. Rock chips were collected at Calhetas $\left(23^{\circ} 45^{\prime} \mathrm{S}, 45^{\circ} 24^{\prime} \mathrm{W}\right)$ on February 15th 2012 $\left(\mathrm{T}_{0}\right), 10 \mathrm{~km}$ away from the Center for Marine Biology (CEBIMar), where the barnacle cover is denser. The CEBIMar is located on the northern coast of São Paulo State, where nearshore conditions are usually oligotrophic, with very sporadic pulse nutrient inputs concentrated during short upwelling events in summer, or during the passage of winter cold fronts, when vertical mixing due to remote forcing takes place (Ciotti et al. 2010). Historical averages of monthly sea surface temperature oscillate from $21.6^{\circ} \mathrm{C}$ to $28.3^{\circ} \mathrm{C}$ (Valentim et al. 2013), consistently above the upper bound of $19.7^{\circ} \mathrm{C}$ estimated for nitrate depletion (Flores et al. 2015) and rendering a generally poor trophic status.

\section{Experimental setup}

Experimental procedures were divided in 2 main phases: an acclimation period of $22 \mathrm{~d}$, from the collection date until March 8th $\left(\mathrm{T}_{\mathrm{a}}\right)$, during which experimental populations were sorted in 2 different feeding regimes, and a subsequent $40 \mathrm{~d}$ period, from March 9th to April 17th $\left(T_{e}\right)$, during which 3 additional pulse manipulations of heat stress were delivered at regular intervals (Fig. 1). All laboratory procedures were conducted at the CEBIMar, in São Sebastião, Brazil.

Acclimation. Experimental populations, consisting of barnacle-covered rock chips, were randomly allocated to 12 experimental aquaria (16 l) maintained at constant temperature $\left(25^{\circ} \mathrm{C}\right)$, natural photoperiod and seawater salinity (around 34 ). In each aquarium, the mean $( \pm \mathrm{SD})$ population size and average barnacle size (operculum diameter) were $412 \pm 33$ ind. and $2.91 \pm 0.07 \mathrm{~mm}$, respectively. Barnacle populations were held in an artificial tidal regime. Filtered seawater ( $3 \mu \mathrm{m}$ pore size), pumped from a reservoir tank (200 l), filled all experimental aquaria for $1 \mathrm{~h}$ during each $12 \mathrm{~h}$ period, simulating high tides. After pumps were switched off, aquaria slowly drained through a hose of $0.5 \mathrm{~cm}$ diameter into sieved containers to retain released larvae. Barnacles were fed a concentrate of 3 microalgal species $\left(3 \times 10^{9}\right.$ cells ml $^{-1}, 1: 1: 1$ Nannochloropsis occulata, Isochrysis galbana and Pavlova lutheri), which is a standard quality hatchery food, rich in essential fatty acids (Seychelles et al. 2009). The lipid characterization of this experimental diet is given in Table S1 (available in the Supplement at www.int-res.com/articles/suppl/m532p161_ supp.pdf). Food supply treatments were calculated based on the total adult barnacle biomass, which was estimated from the dry weight of independent barnacle populations. Low food supply (LF) was $0.6 \%$ of biomass $\left(2.8 \times 10^{7}\right.$ cells $\left.^{-1} \mathrm{~d}^{-1} \mathrm{~g}^{-1}\right)$ and high food supply (HF) was $3.0 \%\left(15.2 \times 10^{7}\right.$ cells $\left.\mathrm{l}^{-1} \mathrm{~d}^{-1} \mathrm{~g}^{-1}\right)$. The lower level was expected to meet minimum requirements for reproduction, as observed in bivalve hatch- 


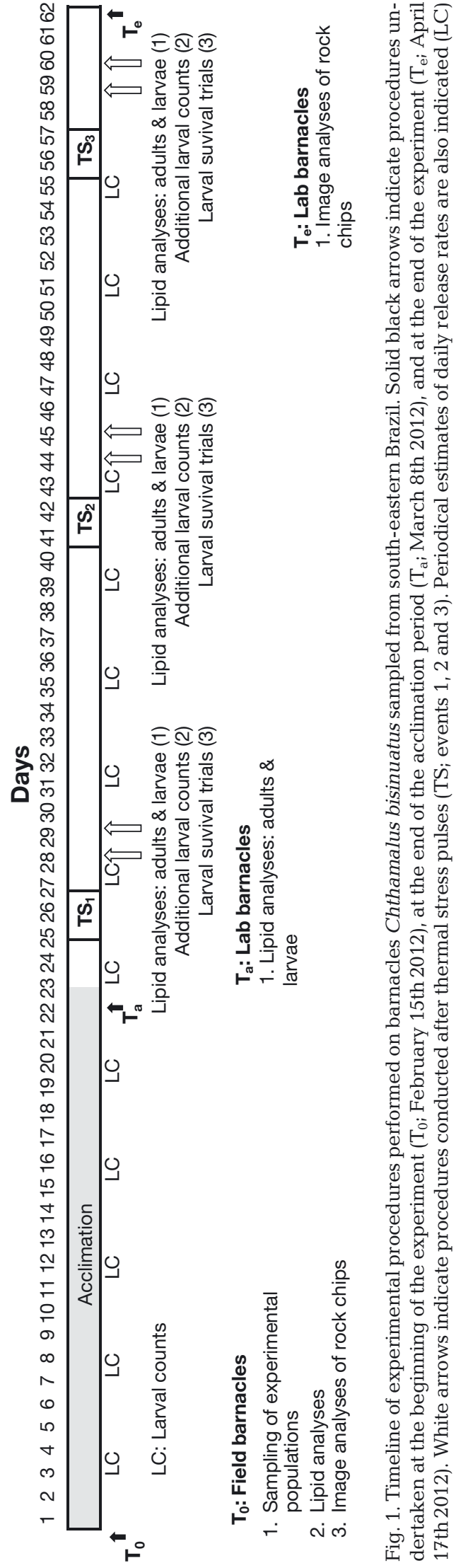

eries (Helm et al. 2004), and was used here as an estimate of food supply just sufficient to ensure basic needs under standard environmental conditions. The physiological condition of larvae $(n=50)$ and adults $(n=5)$ from each aquarium was estimated from samples at $T_{a}$ through lipid analyses. Every $4 \mathrm{~d}$, the water drained from each aquarium after 2 consecutive 'high tides' (daily releases) was filtered through a mesh of $100 \mu \mathrm{m}$, and contents were observed under a stereomicroscope (M3B, Wild Heerbrugg) to count released larvae (Fig. 1). Periodical larval counts and feeding regimes were not restricted to the acclimation period but continued until the end of the experiment.

Manipulations of heat stress. Three days after the end of the acclimation period (Fig. 1), populations were also sorted into 2 thermal treatments, orthogonal to levels of food supply, thus comprising 4 treatment combinations $(\mathrm{n}=3)$. Thermal manipulations involved the transfer of populations from the moist environment in acclimating aquaria to dry BIO stability humidity incubators (Fanem, $347 \mathrm{CDG}$ ), thus imposing reduced humidity. A control treatment aimed to measure responses of populations at the acclimating temperature $\left(25^{\circ} \mathrm{C}\right)$, and a thermal stress treatment was set to measure responses after exposure to $45^{\circ} \mathrm{C}$, comparable to particularly stressful conditions during summer low tide periods. Transfers were conducted at 3 different times (Fig. 1), i.e. thermal stress events $1\left(\mathrm{TS}_{1}\right.$, at Days 25 and 26), 2 ( $\mathrm{TS}_{2}$, at Days 41 and 42$)$ and $3\left(\mathrm{TS}_{3}\right.$, at Days 56 and 57). In each event, populations were transferred to incubators 2 times, on consecutive days. Rocks can hold much of the heat for long periods and, therefore, we started at $\mathrm{TS}_{1}$ by submitting populations to $12 \mathrm{~h}$ periods of thermal stress. However, we observed that barnacles were not feeding shortly after stressed, and suspected this manipulation could be exceedingly injurious. Therefore we reduced stress periods to $6 \mathrm{~h}$ during $\mathrm{TS}_{2}$ and $\mathrm{TS}_{3}$.

\section{Response variables}

Overall trends of adult barnacle performance. Before addressing the performance of adult populations, we compared overall lipid contents and lipid profiles among wild and captive barnacles, acclimated in LF and HF conditions in the laboratory, so as to verify whether the artificial experimental diet affected essential physiological conditions of adult barnacles. Five samples of 5 barnacles, separated by 10 to $20 \mathrm{~m}$, were obtained in the field at the beginning of this study $\left(\mathrm{T}_{0}\right)$, and 5 barnacles were sampled in each of 5 
aquaria allocated to contrasting food supply treatments after acclimation $\left(\mathrm{T}_{\mathrm{a}}\right)$. Changes of overall lipid contents were tested using a 1-way analysis of variance. Changes of lipid profiles were assessed using the equivalent distance-based permutational multivariate analysis of variance (PERMANOVA), with 9999 permutations (Anderson 2001, Anderson et al. 2008) for a single-factor design (natural diet vs. experimental diet), followed by the SIMPER procedure, using the Bray-Curtis similarity matrix, to identify the lipid classes that contributed the most for these differences. The PERMDISP test indicated homoscedasticity, and raw data were used. Separate analyses were used for profiles of neutral and polar lipids because they have distinct physiological roles. While polar lipids, mainly composed of phospholipids, build up primary structural membranes, neutral lipids, chiefly consisting of triacylglycerides, are usually stored as droplets and make up most of the energetic resources available for the individual (Waldock \& Holland 1978, Gallager \& Mann 1986, Delaunay et al. 1993, Lee et al. 2006).

Growth and adult survival were estimated by analyzing images of barnacle populations maintained in each aquarium. All rock chips were photographed with a digital camera at the time they were brought from the field $\left(T_{0}\right)$ to allow measurements of initial barnacle cover and individual size. Photographs were taken again at the end of the experiment $\left(\mathrm{T}_{\mathrm{e}}\right.$ Day 62, April 17th; Fig. 1). Overall growth was measured as increments of the opercular diameter (OD) of a random sample of 10 barnacles per aquarium, which had free adjacent bare rock space allowing horizontal growth. In order to estimate survival, we first quantified adult stocks at the start of the experiment by dividing the cover area of living barnacles by the average area of a single individual, obtained from a random sample of 25 barnacles. The number of new empty barnacle cases at $\mathrm{T}_{\mathrm{e}}$ was then recorded for each population, and survival was calculated as the percentage of barnacles remaining alive. All these analyses were undertaken using the ImageJ software (Schneider et al. 2012). Reproductive effort was measured as the number of larvae released per day, corrected for living barnacle cover area in each aquarium. Release data included both periodical estimates taken at $4 \mathrm{~d}$ intervals, after acclimation, and estimates after pulse stress events (Fig. 1). Therefore, replicate values for each experimental population (= aquarium) consisted of averages calculated from 15 daily counts (Fig. 1). Two-way analyses of variance were run to test for differences in overall larval release and overall adult survival, according to con- ditions of food supply (high vs. low) and whether adults were exposed to thermal stress or not (thermal stress vs. control). Each aquarium provided a single replicate $(\mathrm{n}=3)$. Because measurements for single individuals $(\mathrm{n}=10)$, within each replicate tank, were obtained to examine overall adult growth, a third factor (nested in the interaction of factors 'food supply' and 'thermal stress') was added in this case to test the effect of aquaria. The assumption of homoscedasticity was always met (Cochran's test, $\mathrm{p}>0.05$ in all cases) and therefore raw data were used for all these analyses.

Short-term responses to thermal stress. Reproductive parameters (larval release and larval survival) and physiological traits (lipid profiles) were quantified 2 to $3 \mathrm{~d}$ following manipulations of thermal stress $\left(\mathrm{TS}_{1}, \mathrm{TS}_{2}\right.$ and $\left.\mathrm{TS}_{3}\right)$, to verify any effects of chronic exposure.

Larvae were counted to estimate release rates, as explained above. Seven random replicate larvae, from each aquarium, were used for survival trials after each manipulation. Nauplii were maintained food-deprived in individual $1 \mathrm{ml}$ wells, with a diameter of $10.2 \mathrm{~mm}\left(\right.$ Costar $^{\circledR}$ Cell Culture Clusters plates with 48 wells each), filled with seawater (salinity $\sim 34 \mathrm{ppt}$ ). Well plates containing larvae from different treatments were randomly placed over laboratory bench space with temperature maintained at $25^{\circ} \mathrm{C}$, and inspected daily to check for dead individuals. A 3-way analysis of variance was used to compare larval release across levels 'food supply' (high vs. low), 'thermal stress' (stressed vs. control) and 'time' $\left(\mathrm{TS}_{1}, \mathrm{TS}_{2}\right.$ and $\mathrm{TS}_{3}$ ), which were considered orthogonal, fixed factors. Records for each aquarium were considered replicate values. Because survival was measured for each starved larvae $(n=7)$, a fourth factor had to be included to measure any effects of aquaria on this variable (similarly to what has been explained above for growth of adult barnacles), which was nested in the triple interaction of the 3 main orthogonal factors. The variance of data was homogeneous in both cases, and the SNK procedure was used for a posterori comparisons when needed. For each of these 2 parameters, and separately for each feeding regime, we also compared the data obtained after the acclimation period to data obtained for control and stressed populations after manipulations using $t$-tests.

For lipid analyses, replicate estimates were obtained from 5 adult barnacles (whole individuals without their shells) and 50 larvae in each experimental aquarium. Larvae were all the same age since they were all collected after an artificial 'high tide'. After lipids extraction (see additional methods in the Sup- 
plement), neutral lipids were separated from polar fractions by silica gel $(30 \times 5 \mathrm{~mm}$ i.d., packed with Kieselgel 60, 70-230 mesh; Merck), hydrated with $6 \%$ water, and eluted with $10 \mathrm{ml}$ of dichloromethane: methanol $(98: 2 \mathrm{v} / \mathrm{v})$ for neutral lipids, and then with $20 \mathrm{ml}$ of methanol for polar lipids (Marty et al. 1992). All fatty acid methyl esters (FAMEs) were prepared, purified and analyzed with GC-MSMS. In order to investigate how parents transfer energetic resources to offspring, we first examined the variation of neutral lipid contents for adults and larvae. Second, we evaluated adult uptake of essential fatty acids (EFAs) and their transfer to larvae. The relative buildup of essential fatty acids (EFAs) is considered a measure of their shortage in food sources. Individual to source EFA ratios above 2.0 generally indicate their supply is limiting, while ratios below 1.0 indicate that nutritional requirements were largely satisfied (Copeman et al. 2002). Because we aimed to measure limitation for basic metabolic processes, only the polar EFA fraction in barnacles was used to calculate this ratio. Larval to adult ratios, however, would indicate whether adults retained or preferentially allocated these fatty acids to their offspring. Because adults would only spare lipid reserves, only neutral EFA fractions were considered for both adults and larvae. Comparisons of neutral and essential FAs were undertaken following the orthogonal model of analysis of variance explained above, crossing the factors 'food supply', 'thermal stress' and 'time'. The data for neutral lipid contents in larvae were log-transformed to meet homoscedasticity. In all other cases, raw data were used. For neutral lipids, additional comparisons between responses after acclimation to different feeding regimes and after exposure to thermal stress events were undertaken as above.

\section{RESULTS}

\section{Overall trends of adult barnacle performance}

Physiological condition of adult barnacles acclimated in the laboratory. The total neutral fatty acid contents did not differ among adult barnacles collected directly in the field, barnacles acclimated in $\mathrm{HF}$ and barnacles acclimated in $\mathrm{LF}\left(F_{2,12}=0.16 ; \mathrm{p}=\right.$ 0.86). The comparison of FA profiles of adults from those 3 treatments (field, HF and LF) did not show significant differences for either polar (pseudo- $F=$ $1.54, \mathrm{p}($ perm $)=0.138)$ or neutral lipids (pseudo- $F=$ $0.95 ; \mathrm{p}($ perm $)=0.514)$. Details of FA profiles are given in Table S2 in the Supplement.
Growth and reproductive output. No significant growth was detected for all factor combinations, explaining non-significant main effects of food supply or thermal stress (Table 1). Estimates from each aquarium, within combinations of food supply and thermal stress, averaged $0.00 \mathrm{~mm}$ and ranged from -0.04 to $+0.04 \mathrm{~mm}$. Slight differences among aquaria, although significant, represent random sampling parallax errors because rock chips were not always photographed in a perfectly flat position. In contrast, there were clear differences of overall larval release and survival between control and thermally stressed barnacles, regardless of their food supply (Table 1 , Fig. 2). Control barnacle populations released a mean $( \pm \mathrm{SE})$ of $16.2 \pm 3.1$ nauplii $\mathrm{cm}^{-2} \mathrm{~d}^{-1}$, while stressed populations released $7.6 \pm 0.6$ nauplii $\mathrm{cm}^{-2} \mathrm{~d}^{-1}$, corresponding to a reduction of $53.3 \%$. Survival decreased by $14.7 \%$ from control to stressed populations $(92.3 \pm$ 1.9 to $78.8 \pm 4.2 \%$ ) (Fig. 2). Food supply did not significantly affect these overall parameters (Table 1).
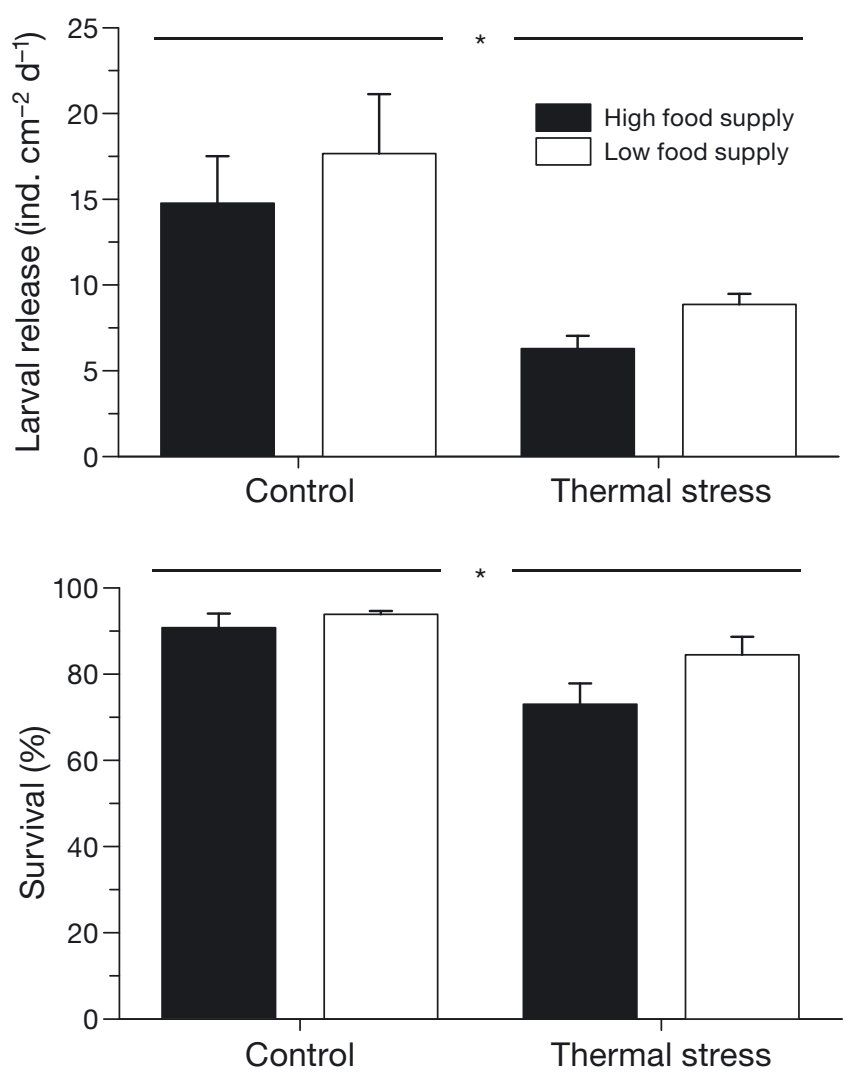

Fig. 2. Two performance indices (survival and larval release) of adult barnacle Chthamalus bisinuatus populations maintained in different combinations of food supply (high vs. low supply) and thermal stress (stressed vs. control). Average values represented by bars under the same horizontal solid line are not statistically different ( $p>0.05)$; asterisks indicate significant differences between control and thermally stressed groups $\left({ }^{*} \mathrm{p}<0.05\right)$. Error bars indicate $+1 \mathrm{SE}$ 
Table 1. Adult barnacle Chthamalus bisinuatus performance: summary results of analyses of variance testing the combined effects of food supply and thermal stress on adult growth (in $\mathrm{mm}$ ), larval release (in ind. $\mathrm{cm}^{-2} \mathrm{~d}^{-1}$ ) and survival (in \%). ${ }^{* * *} \mathrm{p}<$ $0.001 ;{ }^{* *} \mathrm{p}<0.01 ;{ }^{*} \mathrm{p}<0.05$; ns: not significant; $C$ : Cochran's statistic

\begin{tabular}{|c|c|c|c|c|c|c|c|c|}
\hline & \multicolumn{3}{|c|}{ Adult barnacle growth } & \multicolumn{3}{|c|}{ Overall larval release } & \multicolumn{2}{|c|}{ Overall survival } \\
\hline & $\mathrm{df}$ & MS & $F$ & $\mathrm{df}$ & MS & $F$ & MS & $F$ \\
\hline food supply: fs & 1 & 0.0032 & $0.46^{\mathrm{ns}}$ & 1 & 22.48 & $0.97^{\mathrm{ns}}$ & 160.5 & $2.75^{\mathrm{ns}}$ \\
\hline thermal stress: ts & 1 & 0.0006 & $0.09^{\text {ns }}$ & 1 & 223.83 & $9.69^{*}$ & 551.2 & $9.43^{*}$ \\
\hline aquaria(fs $\times$ ts) & 8 & 0.0070 & $4.01^{* * *}$ & - & - & - & - & - \\
\hline fs $x$ ts & 1 & 0.0022 & $0.32^{\text {ns }}$ & 1 & 0.08 & $0.00^{\mathrm{ns}}$ & 52.3 & $0.89^{\text {ns }}$ \\
\hline \multirow[t]{2}{*}{ residual } & 108 & 0.0017 & & 8 & & & & \\
\hline & \multicolumn{3}{|c|}{$\begin{array}{c}\text { Raw data } \\
C=0.1437, p>0.05\end{array}$} & \multicolumn{3}{|c|}{$\begin{array}{c}\text { Raw data } \\
C=0.5857, \mathrm{p}>0.05\end{array}$} & \multicolumn{2}{|c|}{$\begin{array}{c}\text { Raw data } \\
C=0.4460, \mathrm{p}>0.05\end{array}$} \\
\hline
\end{tabular}

\section{Short-term responses to thermal stress: release rate and larval survival}

Larval release rate. Offspring production was greatly affected by thermal stress, but not by food supply (Table 2, Fig. 3). There were no significant differences between responses at different events, but overall release was nearly suppressed in populations exposed to thermal stress. It is important to note, however, that the simple procedure of removing rock chips to control incubators, maintained at ambient temperature, elicited a different response of adult populations, compared to baseline release rates observed after acclimation to feeding regimes. For populations held in the HF regime, control manipulations triggered a much higher release rate than recorded at $\mathrm{T}_{\mathrm{a}}$ (Fig. $3 ; t=1.84, \mathrm{p}=$ 0.04). The same trend was observed for the LF treatment, but in this case lacking statistical support $(t=1.19, \mathrm{p}=$ 0.13). Larval release rate at $T_{a}$ was consistently higher than that measured for populations exposed to thermal stress, regardless of whether they were provided with a low $(t=2.13, \mathrm{p}=$ 0.03 ) or a high food supply $(t=4.44$, $\mathrm{p}<0.001)$.

Larval survival. The length of time unfed larvae remained alive depended on the interaction of experimental factors (Table 2, Fig. 3). Higher than baseline survival was recorded for all treatment combinations of food supply

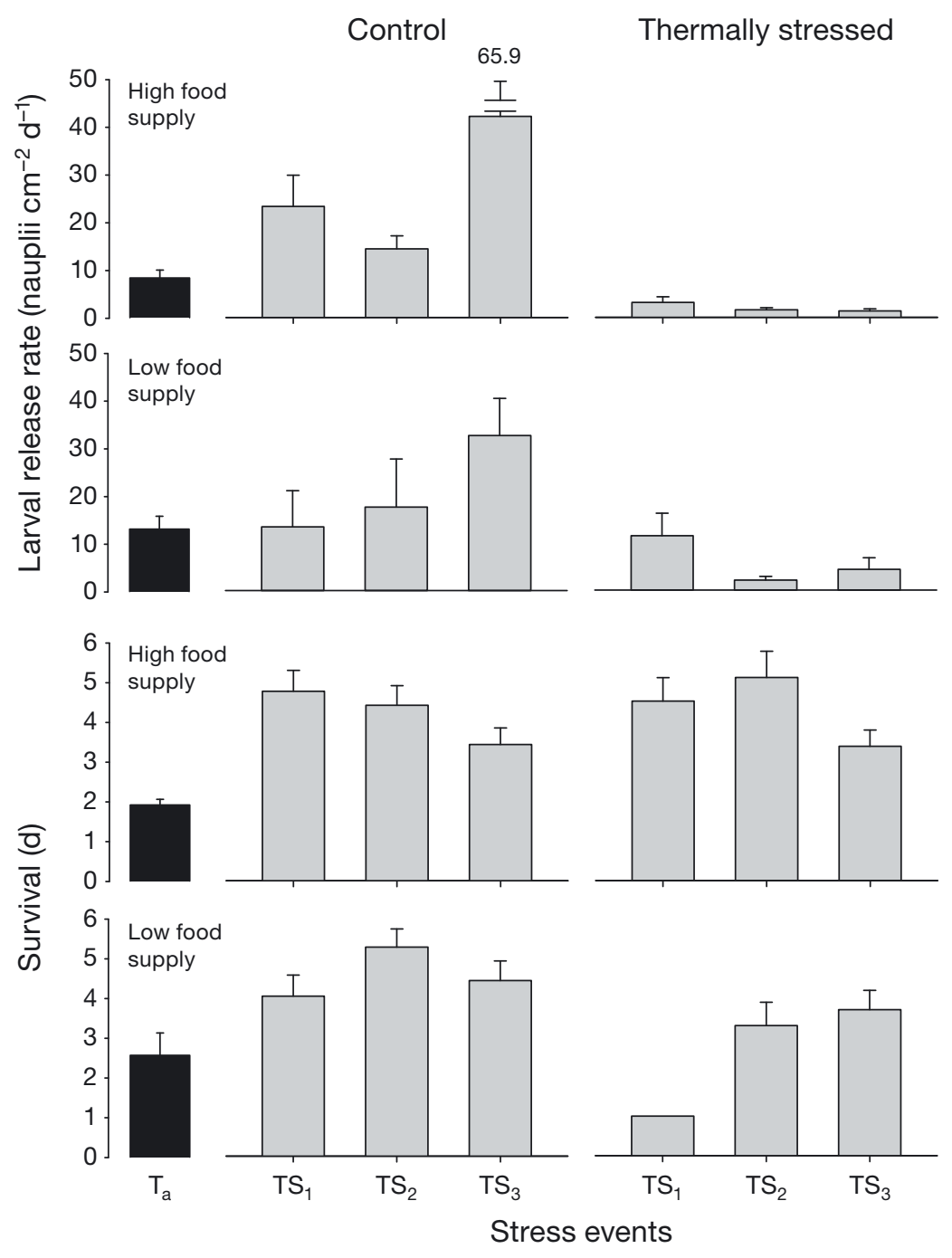

Fig. 3. Short-term reproductive responses of barnacle Chthamalus bisinuatus populations maintained in different combinations of food supply (high vs. low supply) and thermal stress (stressed vs. control). Larval release rate and survival of starved larvae are considered proxies of fecundity and independence of exogenous feeding (= larval quality), respectively. Data were collected during the acclimation period $\left(\mathrm{T}_{\mathrm{a}}\right)$ (black bars) and after 3 stress events $\left(\mathrm{TS}_{1}, \mathrm{TS}_{2}\right.$, $\mathrm{TS}_{3}$ ) (grey bars). Error bars indicate $+1 \mathrm{SE}$ 
Table 2. Short-term responses affecting barnacle larval parameters: summary results of analyses of variance, testing the combined effects of food supply and thermal stress, shortly after stress events, on larval release rate (nauplii $\mathrm{cm}^{-2}$ ind.$^{-1}$ ) and survival of food-deprived larvae (in days). ${ }^{* * *} \mathrm{p}<0.001 ;{ }^{* *} \mathrm{p}<0.01$; ${ }^{*} \mathrm{p}<0.05$; ns: not significant; $C$ : Cochran's statistic

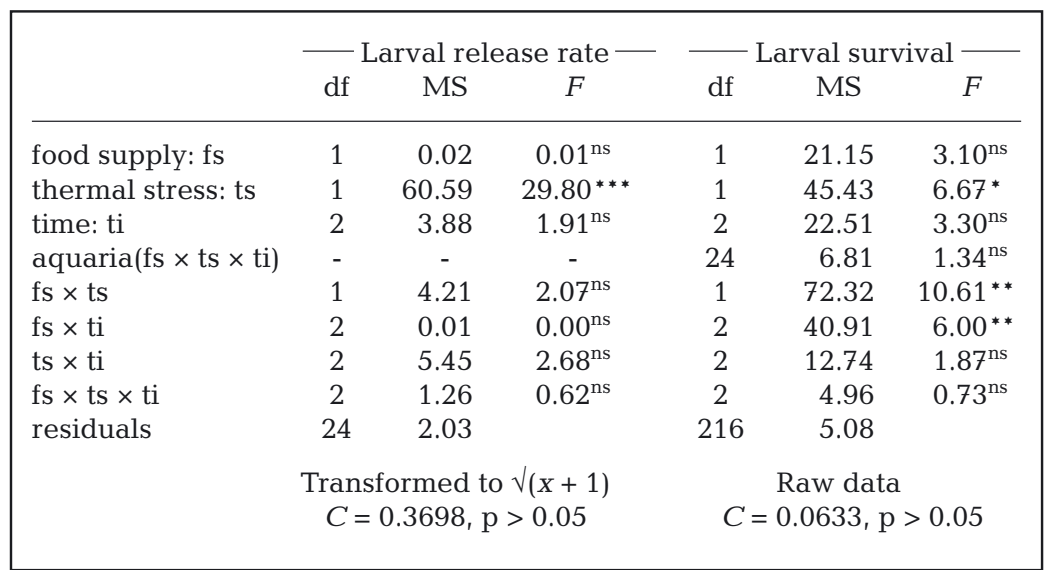

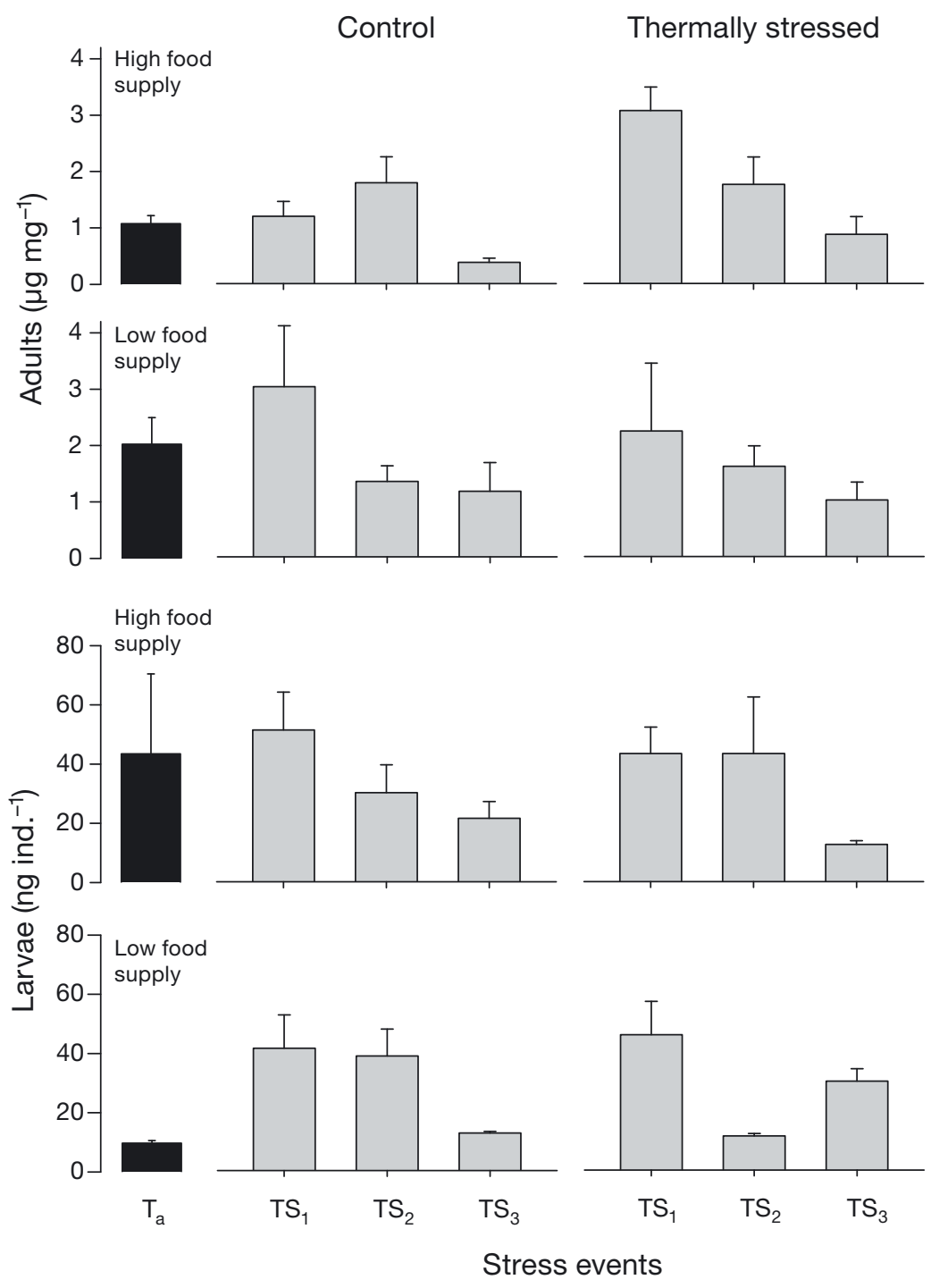

and thermal stress $(3.17<t<3.40, \mathrm{p}<$ 0.01 in all cases), except for larvae released by adults held in low-food concentration and exposed to thermal stress $(t=0.28, \mathrm{p}=0.78)$. This explains the interaction between the factors food supply and thermal stress (Table 2); while larvae released from control and stressed populations in the HF treatment performed in a similar way, survival of nauplii obtained from thermally stressed parents was lower compared to larvae from control populations for the LF treatment (SNK test, $\mathrm{p}<0.01)$. Apart from this interaction, there was also a combined effect of factors food supply and time (Table 2). While there were no significant differences among stress events for the HF treatment, survival was lower for larvae released during $\mathrm{TS}_{1}$, compared to $\mathrm{TS}_{2}$ and $\mathrm{TS}_{3}$ in the LF treatment (SNK test, $\mathrm{p}<0.01$ ).

\section{Short term responses to thermal stress: lipid analyses}

In contrast to larval release rate and larval performance, neutral lipid contents and the transfer of essential fatty acids were mostly influenced by chronic stress, so that responses differed markedly over successive stress events (Figs. 4 \& 5). Therefore, comparisons with baseline values at $T_{a}$ were restricted to $\mathrm{TS}_{1}$, as this would best indicate eventual adaptive physiological responses.

Neutral lipid contents. Before experimental manipulations, the accumulation of neutral lipid reserves was

Fig. 4. Adult reserves of neutral lipids, and their allocation to offspring, for adult barnacle Chthamalus bisinuatus populations maintained in different combinations of food supply (high vs. low supply) and thermal stress (stressed vs. control). Data were collected during the acclimation period $\left(\mathrm{T}_{\mathrm{a}}\right)$ (black bars) and after 3 stress events $\left(\mathrm{TS}_{1}\right.$, $\mathrm{TS}_{2}, \mathrm{TS}_{3}$ ) (grey bars). Error bars indicate $+1 \mathrm{SE}$ 
Control

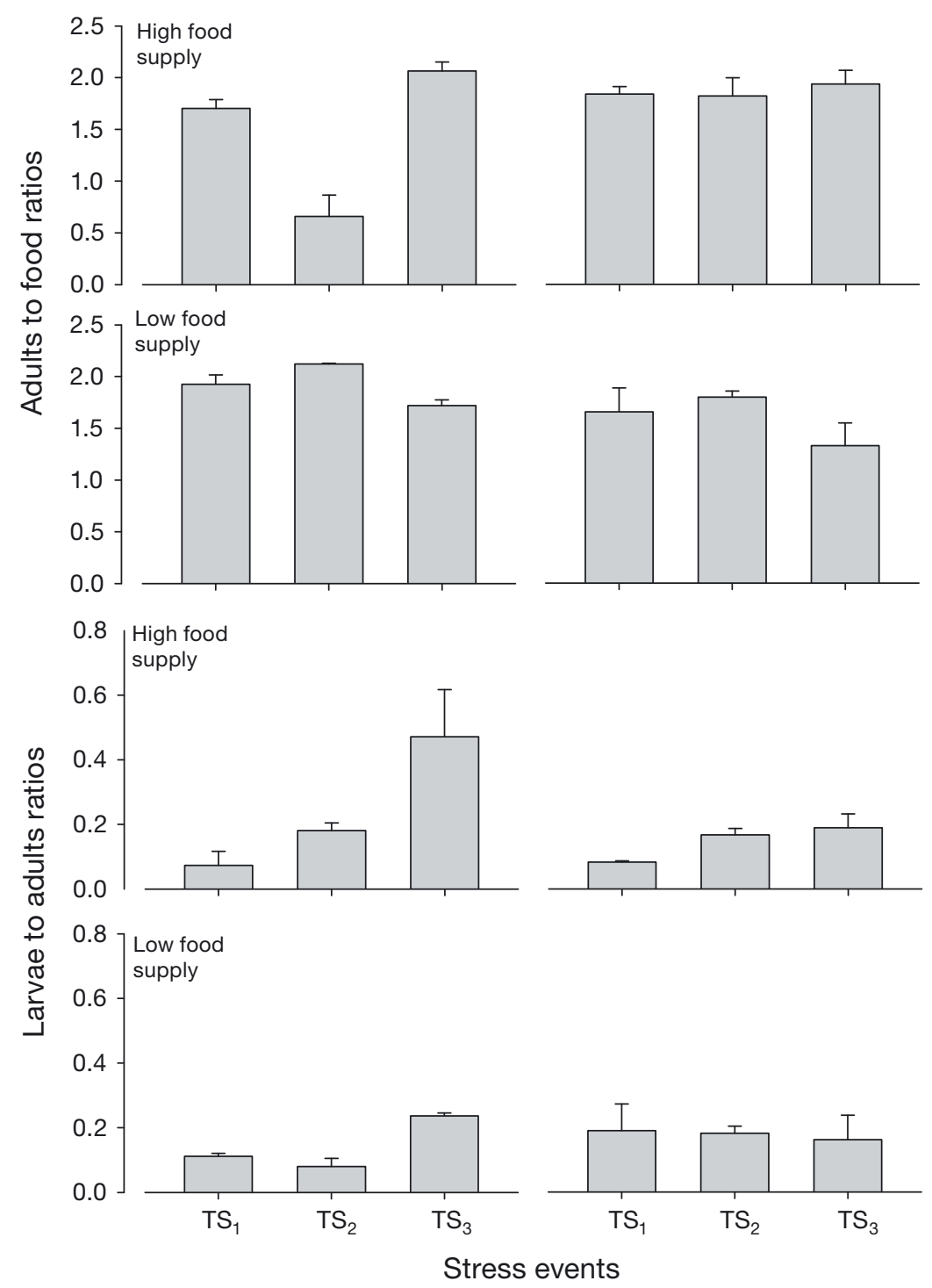

Fig. 5. Relative uptake of essential fatty acids (EFAs) for adult barnacle Chthamalus bisinuatus populations and their transfer to offspring under different food supply (high vs. low) and thermal stress (stressed vs. control). Adult to food (EFA) ratios were almost always higher than 1.0, indicating selection (and thus limitation) of EFAs in experimental diets. Larvae to adult EFA ratios consistently well below 1.0 indicate poor EFA allocation to offspring. Error bars indicate $+1 \mathrm{SE}$

significantly different $(\mathrm{p}<0.05)$ between populations maintained in high and low-food conditions (Fig. 4). Adults acclimated in the HF treatment stored less lipid reserves compared to barnacles held in the LF diet, while the opposite trend was observed for larvae, with those generated by HF parents containing higher contents of neutral lipids compared to nauplii generated by LF parents. This suggests that, spared from thermal stress, parental populations would transfer more resources to larvae when trophic con- ditions are favorable, at the expense of their own reserves, but would retain higher level of reserves when food is scarce, at the price of producing larvae with very low lipid reserves.

Patterns of neutral lipid retention and their transfer to offspring apparently changed when manipulations began. Neutral lipid contents generally declined during the experiment for both adults and larvae (Fig. 4), but there were exceptions to this trend. In adults, food supply or thermal stress did not affect neutral lipid contents (Fig. 4, Table 3), and a decline over time, although more evident for stressed populations, was rather general, with average contents at $\mathrm{TS}_{1}$ being significantly higher than at $\mathrm{TS}_{3}$ (SNK test, $\left.\mathrm{p}<0.05\right)$. Compared to standard contents after acclimation, adults provided a HF diet were able to accumulate much higher energetic lipid contents when first stressed ( $t=4.69, \mathrm{p}=0.002$ ), while no difference was observed for control populations $(t=0.41, \mathrm{p}=0.35)$. Manipulations did not affect the already relatively high allocation of barnacles kept in the LF treatment, regardless of whether they were transferred to control $(t=0.88, \mathrm{p}=0.20)$ or stress chambers $(t=0.18, \mathrm{p}=0.43)$. For larvae, this declining trend was observed for all treatment combinations, except for offspring released by parents maintained under food shortage and exposed to thermal stress (Fig. 4), thus explaining the statistical significance of the third order interaction (Table 3). This was confirmed by pairwise post-hoc comparisons, which detected higher larval lipid contents after $\mathrm{TS}_{1}$ and $\mathrm{TS}_{2}$, compared to $\mathrm{TS}_{3}$ (SNK test, $\mathrm{p}<0.05$ ), except for larvae released by HF adults transferred to control chambers, in which no statistical differences were verified, despite a numerically apparent trend (Fig. 4). For the offspring obtained from barnacles exposed to the least favorable conditions, a pattern over successive stress events was lacking, but post-hoc comparisons indicated that parents managed to transfer a considerable quantity of lipid reserves to larvae after the first stress event, which contrasted to the larval batch produced in the next stress event 
Table 3. Lipid analyses: summary results of analyses of variance testing the combined effects of food supply and thermal stress, shortly after stress events, for total neutral lipids in barnacle adults and larvae (a measure of stored energy), the adult uptake of essential fatty acids (EFAs) from experimental diets (adults to food ratios), and the adult allocation of EFAs to their offspring (larvae to adults ratios). ${ }^{* *} \mathrm{p}<0.001 ;{ }^{* *} \mathrm{p}<0.01 ;{ }^{*} \mathrm{p}<0.05$; ns: not significant; $C$ : Cochran's statistic

\begin{tabular}{|c|c|c|c|c|c|c|c|c|c|}
\hline & \multirow[b]{3}{*}{$\mathrm{df}$} & \multicolumn{4}{|c|}{ Total neutral lipids } & \multicolumn{4}{|c|}{ - Ratios of essential fatty acids } \\
\hline & & \multicolumn{2}{|c|}{ Adults } & \multicolumn{2}{|c|}{ Larvae } & \multicolumn{2}{|c|}{ Adults to food ratio } & \multicolumn{2}{|c|}{ Larvae to adults ratio } \\
\hline & & MS & $F$ & MS & $F$ & MS & $F$ & MS & $F$ \\
\hline food supply: fs & 1 & 0.42 & $0.60^{\text {ns }}$ & 0.05 & $0.53^{\mathrm{ns}}$ & 0.068 & $1.38^{\text {ns }}$ & 0.0312 & $1.47^{\mathrm{ns}}$ \\
\hline thermal stress: ts & 1 & 0.68 & $0.50^{\text {ns }}$ & 0.05 & $0.52^{\text {ns }}$ & 0.008 & $0.17^{\text {ns }}$ & 0.0002 & $0.01^{\mathrm{ns}}$ \\
\hline time: ti & 2 & 7.06 & $0.02^{*}$ & 0.68 & $7.07^{* *}$ & 0.120 & $2.42^{\text {ns }}$ & 0.0679 & $3.2^{\text {ns }}$ \\
\hline fs $\times$ ts & 1 & 2.33 & $0.22^{\mathrm{ns}}$ & 0.12 & $1.29^{\mathrm{ns}}$ & 1.162 & $23.44^{* * *}$ & 0.0145 & $0.68^{\mathrm{ns}}$ \\
\hline $\mathrm{fs} \times \mathrm{ti}$ & 2 & 0.62 & $0.66^{\text {ns }}$ & 0.06 & $0.65^{\text {ns }}$ & 1.085 & $21.88^{* * *}$ & 0.0391 & $1.84^{\mathrm{ns}}$ \\
\hline $\mathrm{ts} \times \mathrm{ti}$ & 2 & 0.16 & $0.89^{\text {ns }}$ & 0.07 & $0.75^{\mathrm{ns}}$ & 0.367 & $7.4^{* *}$ & 0.0720 & $3.39^{*}$ \\
\hline $\mathrm{fs} \times \mathrm{ts} \times \mathrm{ti}$ & 2 & 1.74 & $0.32^{\text {ns }}$ & 0.38 & $3.95^{*}$ & 0.335 & $6.76^{* *}$ & 0.0111 & $0.52^{\text {ns }}$ \\
\hline \multirow[t]{2}{*}{ residual } & 24 & 1.46 & & 0.10 & & 0.050 & & 0.0213 & \\
\hline & \multicolumn{3}{|c|}{$\begin{array}{c}\text { Raw data } \\
C=0.3783, p>0.05\end{array}$} & \multicolumn{2}{|c|}{$\begin{array}{c}\text { Transformed to } \ln (x+1) \\
C=0.3178, p>0.05\end{array}$} & \multicolumn{2}{|c|}{$\begin{array}{c}\text { Raw data } \\
C=0.2686, p>0.05\end{array}$} & \multicolumn{2}{|c|}{$\begin{array}{c}\text { Raw data } \\
C=0.3743, p>0.05\end{array}$} \\
\hline
\end{tabular}

(SNK, $\mathrm{p}<0.05$ ), which was the most poorly provided among all treatment combinations. Relative to postacclimation standards, parental provision to larvae remained high for $\mathrm{HF}$ populations after $\mathrm{TS}_{1}$, no matter whether adults were transferred to control $(t=$ $0.25, \mathrm{p}=0.41)$ or stress chambers $(t=0.001, \mathrm{p}=0.49)$. However, parents held in the LF treatment greatly increased the transfer of neutral lipids after $\mathrm{TS}_{1}$ for both the control $(t=3.67, \mathrm{p}=0.007)$ and the thermally stressed groups $(t=3.55, \mathrm{p}=0.006)$.

Essential fatty acids. Results suggested that EFAs were markedly limiting in experimental diets, and that adults are capable of selectively uptaking EFAs. Except for the average value estimated after $\mathrm{TS}_{2}$ for HF barnacles in the control treatment, which differed from $\mathrm{TS}_{1}$ and $\mathrm{TS}_{3}$ in the same level combination of these factors (SNK test, $\mathrm{p}<0.01$ ), adults to food EFA ratios remain relatively constant, between 1.3 and 2.1 (Fig. 5). Besides that difference, there was also a slight, but significant, (SNK test, $\mathrm{p}<0.05$ ) difference between the ratios measured after $\mathrm{TS}_{2}$ and $\mathrm{TS}_{3}$ for stressed individuals kept in LF conditions (Fig. 5), explaining the significant 3-order interaction in Table 3.

In spite of adult barnacles being capable of preferably uptaking EFAs in their diet, parental barnacles did not transfer proportional shares of EFAs to their offspring, which would translate to a larvae to adults ratio of 1.0. Rather, these ratios ranged from only 0.1 to 0.2 across level combinations, except after $\mathrm{TS}_{3}$, for larvae released by control $\mathrm{HF}$, in which this ratio surpassed 0.4 (Fig. 5). In fact, larval to adult ratios from the control treatment, HF and LF populations included, exhibited a low but increasing trend over successive manipulations, and hence the significant interaction between factors 'thermal stress' and 'time' in Table 3.

\section{DISCUSSION}

\section{Reproductive strategy and adaptive significance}

Our study provided evidence that reproductive strategies of upper shore barnacles Chtamalus bisinuatus facing environmental stressors are complex and cannot be labeled as simply selfish or altruistic (= anticipatory) from a parental viewpoint. While stressful conditions imposing a higher mortality rate may substantially decrease overall offspring production, consistent with resource allocation to their own needs, short-term responses to experimental manipulations diverged into opposite tactics, depending on stress level. Results showed that reproductive restrictions in this tropical barnacle species affected not only larval release rate, but also larval quality, measured as survival of food-deprived nauplii. While variability of offspring quality is very well documented and interpreted for species producing lecithotrophic larvae (e.g. Marshall \& Keough 2004, Allen et al. 2008, Collin \& Salazar 2010), factors influencing the quality of planktotrophic larvae are much less understood, particularly in an oligotrophic environment such as the tropical area sampled in this study. In the particular case of barnacles, several studies have measured the quality of the last larval stage, the cyprid, as a means to predict success at metamorphosis and juvenile performance (e.g. Jarrett \& Pechenik 1997, Miron et al. 2000, Olivier et al. 2000, Thiyagarajan et al. 2003, Tremblay et al. 2007b), which should largely reflect patterns of food supply in the water column during larval development. As far as we are aware, however, this is the first contribution testing environmentally-driven parental effects 
on early larval quality; a process that may substantially affect pelagic larval survival.

Overall adult performance, in terms of their survival and the number of offspring produced, depended on whether or not they were exposed to thermal stress, but not on food supply. Apparently, the 2 food treatments applied in this study provided sufficient resources to maintain overall adult performance. Populations exposed to short thermal stress events exhibited a slightly lower survival but a marked decrease in the numbers of larvae released, possibly due to physiological constraints, as suggested for other aquatic invertebrates exposed to different stress sources (e.g. Lawrence \& Herrera 2000, Feldmannová et al. 2006). Barnacles did not show any significant growth during any combination of the experimental factors tested, and therefore trade-offs are only discussed in terms of adult survival and the quantity and quality of the larvae they produced. Short-term responses reinforce overall trends indicating that adults drastically reduce larval release rate when thermally stressed. However, a careful interpretation of results indicates that this is only part of a more complex behavior. Transfers of experimental adult populations to BIO chambers, both from control and thermally stressful incubators, imposed a decrease in the relative air humidity. This apparently elicited some differential response compared to what was observed at the end of the acclimation period, when rock chips remained in the more humid environment of experimental aquaria. Therefore, the control treatment should be better viewed as an intermediate condition (+ desiccation stress) between the more amenable environment inside experimental tanks, subjected to artificial tides, and the thermal stress treatment (+ desiccation stress, + thermal stress). In this scenario, larval production was maximum in intermediate conditions, as shown by the well-fed adult populations which experienced the highest release rates (near 70 nauplii $\mathrm{cm}^{-2} \mathrm{~d}^{-1}$ ) when transferred to control chambers. While we offer no support for the terminal investment hypothesis advanced by Kasten \& Flores (2013), because stressful conditions under which some differential mortality occurred caused a decrease (not an expected increase) in larval release rate, our results do suggest that an intermediate level of stress maximizes the transfer of resources to the production of nauplii. This set of results indicates that reproductive strategies may depend on the level of the stressing agent, as reported for copepods acclimated to polluted conditions, which exhibit highest egg production at intermediate copper concentrations (Moraitou-Apostolo- poulou \& Verriopoulos 1979), and anemone fish exposed to acidified seawater, which formed mating pairs more frequently under moderate experimental change (Miller et al. 2013). Considering that adults were not allocating any resources to their growth, and therefore not investing in an enhanced fecundity allowed by an increase in size, the redirection of energetic reserves to offspring production at intermediate stress levels may be viewed as an anticipatory maternal effect. Optimal fitness, as recruitment rate, would then be a result of intensified larval release rate, rather than the outcome of parental embryonic manipulation. On the other hand, when adults were exposed to a high stress level, larval release dropped to very low numbers, suggesting either a physiological constraint, or a selfish strategy in which conserving resources would minimize adult mortality under life-threatening conditions.

Short-term responses do not only impose decreased larval production, but also imply differences in larval quality. In this study, we examined how long larvae could survive without external food resources-a parameter that best reflects how larvae would cope with the frequent oligotrophic conditions in the tropical nearshore environment. In line with what was observed for larval release rate, parents exposed to intermediate stress levels released higher-quality larvae which survived longer during starvation conditions. Higher quality larvae lived on average for $4 \mathrm{~d}$ compared to a baseline average of $2 \mathrm{~d}$ recorded for nauplii released by parents at the end of the acclimation period. Parents subjected to intense stress events may also produce larvae with improved performance, but only when reared with a high food supply. Taken together, results from this study suggest that parental C. bisinuatus exposed to acute thermal stress will first respond by reducing the number of offspring while providing them with additional reserves to help resist starvation, and, when additionally subjected to suboptimal food supply, parents will then restrict resource allocation which results in decreased larval quality. Although broadly considered as planktotrophic, our results demonstrate that the performance of early barnacle nauplii may greatly depend on the level of resource allocation to embryos. Parental strategy may thus shift from selfish, by investing little in each larva when environmental conditions are optimal and larvae may encounter suitable conditions for their development, to anticipatory, when adults face intermediate stress and future reproduction is uncertain. Under high stress level and without abundant food, investment per offspring decreases to baseline standards, in this 
case probably because adults become impaired. It should be noted, however, that it is difficult to assess how food restrictions imposed in this experiment correspond to food limitation in nature. Even if adequate estimates of average supply of suspended organic matter were available, which would be a very challenging task given its extreme variability in coastal waters, there is still no consensus of which organic particles actually constitute potential food items (Vargas et al. 2006).

\section{Ecological implications}

From an ecological perspective, this overall reproductive strategy may be adaptive for different reasons. Mild conditions of temperature and humidity and the absence of disrupting stressors, as offered to experimental populations during the acclimation period, cue favorable habitat conditions and low adult mortality risk. In these circumstances, a more even temporal distribution of reproductive effort, with low baseline release rates of relatively poorer larvae, may be advantageous in the long run because there will be reasonable chances of long-living barnacles producing some of their offspring under favorable pelagic conditions for planktotrophy. This is consistent with lifehistory theory which predicts low reproductive intensity when life expectancy is high (Calow 1979, Reznick 1985, Müller et al. 2001), and when the supply of resources to offspring is uncertain (Murphy 1968, Hirshfield \& Tinkle 1975, Giesel 1976), as is frequently the case for food availability in the nearshore water column. However, in contrast to the relatively stable environment in which acclimating barnacles were held, sudden changes of key physical factors, often coinciding with major shifts in the trophic state of the pelagic environment, may trigger reproductive activity and thus affect the performance of eggs or larvae (Shanks 1998, Bueno et al. 2010). The contrasting response of adults facing potential desiccation stress, typical of hot sunny days, in which high-quality larvae are produced in larger, more discrete events, may compensate for the poor oligotrophic state that commonly follows high-pressure atmospheric conditions leading to prolonged stratification and fast depletion of nutrients (Peeters \& Peperzak 1990, Strom \& Fredrickson 2008). Under these conditions, doubling the duration of starvation resistance will provide important additional time to cope with environmental change, and thus increased chances for larvae to find a suitable resource supply and resume development toward competency and settlement.

\section{Underlying physiological mechanisms}

The fast physiological responses to thermal stress reported in this study are compatible with the general dynamics of endocrine control acting on lipid synthesis and mobilization in crustaceans (O'Connor \& Gilbert 1968). Contrary to most lecithotrophic larvae and the later cyprid stage of larval barnacles, we found no clear relationship between parental transfer of neutral lipid reserves and early naupliar performance. For instance, acclimating parents reared with different diets, and allocating quite different amounts of lipid reserves to their embryos, produced larvae that performed similarly. Also, the overall decreasing trend of neutral lipid contents over time was not matched by a similar tendency for larval performance. It is possible, however, that we stopped the experiment before the capacity of neutral lipid storage by adults (and its transfer to embryos) had become critical for larval performance. Within the range of environmental conditions established in this study, it is likely that the relatively stable larval performance in each treatment combination of main factors (thermal stress and food supply) is the result of a compensatory effect of increasing transfer of essential fatty acids, from adults to larvae, as the capacity of neutral lipid storage declines. Seemingly, adults can rapidly store neutral lipids (1-2 d) and transfer them to larvae in a proportional fashion, suggesting little manipulation once parents build up these reserves. In contrast, patterns of adult EFA uptake from the experimental diet and subsequent EFA transfer to embryos were uncoupled. In general, adults were capable of selectively assimilating and retaining EFAs across treatments and over time, indicating that their supply might be usually insufficient in nature, leaving only a small fraction for larval production. However, this fraction tended to slightly increase over the experimental time frame, in spite of a general constant EFA uptake by adults from their food sources. The exception was the case for adults subjected to both thermal stress and food shortage, which could not increase the share of EFAs to their offspring, hence remaining below 0.2. This would explain why larvae of adults subjected to both stressors exhibited the worst performance. While the transfer of EFAs might be critical for optimal larval development, it should be pointed out that other physiological mechanisms, such as those related to the metabolism of carbohydrates, as observed in bivalve larvae (Whyte et al. 1989, Tremblay et al. 2007a), can play an important role in naupliar survival and growth and thus should be examined in further studies. 
Acknowledgements. We sincerely thank Dr. Philippe Archambault and Dr. Fréderic Olivier for guidance and criticism which greatly improved this manuscript. Lipid analyses required considerable expertise and could not have been undertaken without the help of several members of the aquaculture laboratory at ISMER; namely, Sahar Mejri, Iften Redjah, Bertrand Genard, Jory Cabrol, Jean-Bruno Nadalini and Mathieu Babin. Many people provided essential help both in the field and laboratory while in Brazil. We are especially thankful to the CEBIMar/USP technical staff, Joseilto M. de Oliveira, Elso A. da Silva, Eduardo Honuma and Joseph Sebroeck, and to several colleagues, especially Pedro Guerra, Paula Kasten, Jandyr Filho, Maria S. Lopez, Sergio A. C. Sousa and Bruno Sayão. Financial support was provided by FAPESP as research projects \#2008/10085-5 and \#2013/01446-2 granted to A.A.V.F. and by the Natural Sciences and Engineering Research Council of Canada (Discovery grant) to R.T. This is a contribution of the Research Centre for Marine Biodiversity of the University of São Paulo (NP-Biomar/USP).

\section{LITERATURE CITED}

Achituv Y, Blackstock J, Barnes M, Barnes H (1980) Some biochemical constituents of stage I and II nauplii of Balanus balanoides (L.) and the effect of anoxia on stage I. J Exp Mar Bio Ecol 42:1-12

Allen RM, Buckley YM, Marshall DJ (2008) Offspring size plasticity in response to intraspecific competition: an adaptive maternal effect across life-history stages. Am Nat 171:225-237

Anderson MJ (2001) A new method for non-parametric multivariate analysis of variance. Austral Ecol 26:32-46

Anderson MJ, Gorley RN, Clarke KR (2008) PERMANOVA+ for PRIMER: guide to software and statistical methods. PRIMER-E, Plymouth

> Berger MS (2009) Reproduction of the intertidal barnacle Balanus glandula along an estuarine gradient. Mar Ecol 30:346-353

> Bertram DF, Strathmann RR (1998) Effects of maternal and larval nutrition on growth and form of planktotrophic larvae. Ecology 79:315-327

Bueno M, Moser GAO, Tocci BRC, Flores AAV (2010) Retention-favorable timing of propagule release in barnacles and periwinkles. Mar Ecol Prog Ser 414:155-165

Calow P (1979) The cost of reproduction - a physiological approach. Biol Rev Camb Philos Soc 54:23-40

Chan BKK, Morritt D, De Pirro M, Leung KMY, Williams GA (2006) Summer mortality: effects on the distribution and abundance of the acorn barnacle Tetraclita japonica on tropical shores. Mar Ecol Prog Ser 328:195-204

Christofoletti RA, Takahashi CK, Oliveira DN, Flores AAV (2011) Abundance of sedentary consumers and sessile organisms along the wave exposure gradient of subtropical rocky shores of the south-west Atlantic. J Mar Biol Assoc UK 91:961-967

Ciotti AM, Garcia CAE, Jorge DSF (2010) Temporal and meridional variability of satellite-estimates of surface chlorophyll concentration over the Brazilian continental shelf. Pan-Am J Aquat Sci 5:236-253

Collin R, Salazar MZ (2010) Temperature-mediated plasticity and genetic differentiation in egg size and hatching size among populations of Crepidula (Gastropoda: Calyptraeidae). Biol J Linn Soc 99:489-499
Copeman LA, Parrish CC, Brown JA, Harel M (2002) Effects of docosahexaenoic, eicosapentaenoic, and arachidonic acids on the early growth, survival, lipid composition and pigmentation of yellowtail flounder (Limanda ferruginea): a live food enrichment experiment. Aquaculture 210:285-304

> Cotter SC, Ward RJS, Kilner RM (2011) Age-specific reproductive investment in female burying beetles: independent effects of state and risk of death. Funct Ecol 25:652-660

> Delaunay F, Marty Y, Moal J, Samain JF (1993) The effect of monospecific algal diets on growth and fatty acid composition of Pecten maximus (L. ) larvae. J Exp Mar Biol Ecol 173:163-179

> Desai DV, Anil AC (2005) Recruitment of the barnacle Balanus amphitrite in a tropical estuary: implications of environmental perturbation, reproduction and larval ecology. J Mar Biol Assoc UK 85:909-920

Eckelbarger KJ (1994) Diversity of metazoan ovaries and vitellogenic mechanisms: implications for life history theory. Proc Biol Soc Wash 107:193-218

Feldmannová M, Hilscherová K, Maršálek B, Bláha L (2006) Effects of N-heterocyclic polyaromatic hydrocarbons on survival, reproduction, and biochemical parameters in Daphnia magna. Environ Toxicol 21:425-431

Flores AAV, Christofoletti RA, Peres ALF, Ciotti AM, Navarrete SA (2015) Interactive effects of grazing in subtropical rocky shores: modulation of bottom-up inputs by wave action. J Exp Mar Biol Ecol 463:39-48

Gallager SM, Mann R (1986) Growth and survival of larvae of Mercenaria mercenaria (L.) and Crassostrea virginica (Gmelin) relative to broodstock conditioning and lipid content of eggs. Aquaculture 56:105-121

> Giesel JT (1976) Reproductive strategies as adaptations to life in temporally heterogeneous environments. Annu Rev Ecol Syst 7:57-79

Glencross BD (2009) Exploring the nutritional demand for essential fatty acids by aquaculture species. Rev Aquac 1:71-124

Groothuis TGG, Müller W, von Engelhardt N, Carere C, Eising C (2005) Maternal hormones as a tool to adjust offspring phenotype in avian species. Neurosci Biobehav Rev 29:329-352

Helm MM, Bourne N, Lovatelli A (2004) Hatchery culture of bivalves. A practical manual. FAO Fish Tech Pap. FAO, Rome

- Hirshfield MF, Tinkle DW (1975) Natural selection and the evolution of reproductive effort. Proc Natl Acad Sci USA 72:2227-2231

Inatsuchi A, Yamato S, Yusa Y (2010) Effects of temperature and food availability on growth and reproduction in the neustonic pedunculate barnacle Lepas anserifera. Mar Biol 157:899-905

> Jarrett JM, Pechenik JA (1997) Temporal variation in cyprid quality and juvenile growth capacity for an intertidal barnacle. Ecology 78:1262-1265

Javoiš J, Tammaru T (2004) Reproductive decisions are sensitive to cues of life expectancy: the case of a moth. Anim Behav 68:249-255

Kasten P, Flores AAV (2013) Disruption of endogenous tidal rhythms of larval release linked to food supply and heat stress in an intertidal barnacle. Mar Ecol Prog Ser 472: 185-198

Kozlowski J (1992) Optimal allocation of resources to growth and reproduction: implications for age and size at maturity. Trends Ecol Evol 7:15-19 
Lawrence JM, Herrera J (2000) Stress and deviant reproduction in echinoderms. Zool Stud 39:151-171

> Lee RF, Hagen W, Kattner G (2006) Lipid storage in marine zooplankton. Mar Ecol Prog Ser 307:273-306

> Leslie HM, Breck EN, Chan F, Lubchenco J, Menge BA (2005) Barnacle reproductive hotspots linked to nearshore ocean conditions. Proc Natl Acad Sci USA 102: 10534-10539

- Lewis JB (1963) Environmental and tissue temperatures of some tropical intertidal marine animals. Biol Bull 124: $277-284$

> Lucas MI, Walker G, Holland DL, Crisp DJ (1979) An energy budget for the free-swimming and metamorphosing larvae of Balanus balanoides (Crustacea: Cirripedia). Mar Biol 55:221-229

Marañón E, Holligan PM, Varela M, Mouriño B, Bale AJ (2000) Basin-scale variability of phytoplankton biomass, production and growth in the Atlantic Ocean. Deep-Sea Res I 47:825-857

Marshall DJ, Keough MJ (2004) When the going gets rough: effect of maternal size manipulation on larval quality. Mar Ecol Prog Ser 272:301-305

Marshall DJ, Uller T (2007) When is a maternal effect adaptive? Oikos 116:1957-1963

> Marty Y, Delaunay F, Moal J, Samain JF (1992) Changes in the fatty acid composition of Pecten maximus (L.) during larval development. J Exp Mar Biol Ecol 163:221-234

> McEdward LR (1986) Comparative morphometrics of echinoderm larvae. I. Some relationships between egg size and initial larval form in echinoids. J Exp Mar Biol Ecol 96:251-265

Miller GM, Watson SA, McCormick MI, Munday PL (2013) Increased $\mathrm{CO}_{2}$ stimulates reproduction in a coral reef fish. Glob Chang Biol 19:3037-3045

Miron G, Walters LJ, Tremblay R, Bourget E (2000) Physiological condition and barnacle larval behavior: a preliminary look at the relationship between TAG/DNA ratio and larval substratum exploration in Balanus amphitrite. Mar Ecol Prog Ser 198:303-310

Moraitou-Apostolopoulou M, Verriopoulos G (1979) Some effects of sub-lethal concentrations of copper on a marine copepod. Mar Pollut Bull 10:88-92

Morgan SG (1995) Life and death in the plankton: larval mortality and adaptation. In: McEdward L (ed) Ecology of marine invertebrate larvae. CRC Press, Boca Raton, FL, p 279-321

Mousseau TA, Dingle H (1991) Maternal effects in insect life histories. Annu Rev Entomol 36:511-534

Mousseau TA, Fox CW (1998) The adaptive significance of maternal effects. Trends Ecol Evol 13:403-407

Müller HG, Carey JR, Wu D, Liedo P, Vaupel JW (2001) Reproductive potential predicts longevity of female Mediterranean fruitflies. Proc R Soc Lond B 268:445-450

Murphy GI (1968) Pattern in life history and the environment. Am Nat 102:391-403

> O'Connor JD, Gilbert LI (1968) Aspects of lipid metabolism in crustaceans. Am Zool 8:529-539

> Olivier F, Tremblay R, Bourget E, Rittschof D (2000) Barnacle settlement: field experiments on the influence of larval supply, tidal level, biofilm quality and age of Balanus amphitrite cyprids. Mar Ecol Prog Ser 199: 185-204

Olson RR, Olson MH (1989) Food limitation of planktotrophic marine invertebrate larvae: does it control recruitment success? Annu Rev Ecol Syst 20:225-247
Palmer JR, Totterdell IJ (2001) Production and export in a global ocean ecosystem model. Deep-Sea Res I 48: 1169-1198

Peeters JCH, Peperzak L (1990) Nutrient limitation in the North Sea: a bioassay approach. Neth J Sea Res 26:61-73

Pernet F, Tremblay R (2004) Effect of varying levels of dietary essential fatty acids during early ontogeny of the sea scallop Placopecten magellanicus. J Exp Mar Biol Ecol 310:73-86

> Poorbagher H, Lamare MD, Barker MF (2010) The relative importance of parental nutrition and population versus larval diet on development and phenotypic plasticity of Sclerasterias mollis larvae. J Mar Biol Assoc UK 90: 527-536

Reznick D (1985) Costs of reproduction: an evaluation of the empirical evidence. Oikos 44:257-267

> Roitberg BD, Sircom J, Roitberg CA, van Alphen JJM, Mangel M (1993) Life expectancy and reproduction. Nature 364:108

Rumrill SS (1990) Natural mortality of marine invertebrate larvae. Ophelia 32:163-198

> Schneider CA, Rasband WS, Eliceiri KW (2012) NIH Image to ImageJ: 25 years of image analysis. Nat Methods 9: 671-675

Seychelles L, Audet C, Tremblay R, Fournier R, Pernet F (2009) Essential fatty acid enrichment of cultured rotifers (Brachionus plicatilis) using frozen-concentrated microalgae. Aquac Nutr 15:431-439

Shanks AL (1998) Apparent oceanographic triggers to the spawning of the limpet Lottia digitalis (Rathke). J Exp Mar Biol Ecol 222:31-41

Strom SL, Fredrickson KA (2008) Intense stratification leads to phytoplankton nutrient limitation and reduced microzooplankton grazing in the southeastern Bering Sea. Deep-Sea Res II 55:1761-1774

Thiyagarajan V, Nancharaiah Y, Venugopalan V, Nair K, Subramoniam T (2000) Relative tolerance of cirripede larval stages to acute thermal shock: a laboratory study. J Therm Biol 25:451-457

Thiyagarajan V, Harder T, Qian P (2002) Relationship between cyprid energy reserves and metamorphosis in the barnacle Balanus amphitrite Darwin (Cirripedia; Thoracica). J Exp Mar Biol Ecol 280:79-93

Thiyagarajan V, Harder T, Qiu JW, Qian PY (2003) Energy content at metamorphosis and growth rate of the early juvenile barnacle Balanus amphitrite. Mar Biol 143: 543-554

Tremblay R, Cartier S, Miner P, Pernet F and others (2007a) Effect of Rhodomonas salina addition to a standard hatchery diet during the early ontogeny of the scallop Pecten maximus. Aquaculture 262:410-418

Tremblay R, Olivier F, Bourget E, Rittschof D (2007a) Physiological condition of Balanus amphitrite cyprid larvae determines habitat selection success. Mar Ecol Prog Ser 340:1-8

Valentim SS, Bernardes MEC, Dottori M, Cortezi M (2013) Low-frequency physical variations in the coastal zone of Ubatuba, northern coast of São Paulo State, Brazil. Braz J Oceanogr 61:187-193

van Noordwijk AJ, de Jong G (1986) Acquisition and allocation of resources: their influence of variation in life history tactics. Am Nat 128:137-142

> Vargas CA, Manríquez PH, Navarrete SA (2006) Feeding by larvae of intertidal invertebrates: assessing their position in pelagic food webs. Ecology 87:444-457 
Waldock MJ, Holland DL (1978) Fatty acid composition of the triacylglycerols of the cypris larva of the barnacle Balanus balanoides during metamorphosis. Mar Biol 46: 163-166

Whyte JNC, Bourne N, Hodgson CA (1989) Influence of algal diets on biochemical composition and energy reserves in Patinopecten yessoensis (Jay) larvae. Aquaculture 78:333-347

Williams GA (1994) The relationship between shade and molluscan grazing in structuring communities on a moderately-exposed tropical rocky shore. J Exp Mar Biol Ecol

Editorial responsibility: Pei-Yuan Qian,

Kowloon, Hong Kong SAR
178:79-95

Williams GA, Morritt D (1995) Habitat partitioning and thermal tolerance in a tropical limpet, Cellana grata. Mar Ecol Prog Ser 124:89-103

Yamamoto H, Shimizu K, Tachibana A, Fusetani N (1999) Roles of dopamine and serotonin in larval attachment of the barnacle, Balanus amphitrite. J Exp Zool 284: $746-758$

Yuen B, Hoch JM (2010) Factors influencing mating success in the acorn barnacle, Semibalanus balanoides. J Crustac Biol 30:373-376

Submitted: October 15, 2014; Accepted: May 29, 2015

Proofs received from author(s): July 13, 2015 